\title{
Correction to: The effect of prescribed burning on the drought resilience of Pinus nigra ssp. salzmannii Dunal (Franco) and $P$. sylvestris $\mathrm{L}$.
}

\author{
Teresa Valor $^{1}$ • Giovanna Battipaglia ${ }^{2}$ - Míriam Piqué ${ }^{1} \cdot$ Simona Altieri $^{2}$ • José Ramón González-Olabarria ${ }^{1}$. \\ Pere Casals ${ }^{1}$
}

Published online: 18 March 2020

(C) INRAE and Springer-Verlag France SAS, part of Springer Nature 2020

Correction to: Annals of Forest Science (2020) 77:13 https://doi.org/10.1007/s13595-019-0912-1

The article was originally published with duplicate information appearing in the work. The article has been updated and corrected with the removal of the duplicate material. The original article has been corrected.

The article was originally published with duplicate information appearing in the work. The article has been updated and corrected with the removal of the duplicate material.

The online version of the original article can be found at https://doi.org/ 10.1007/s13595-019-0912-1

Teresa Valor

teresa.valor@ctfc.es

Giovanna Battipaglia

giovanna.battipaglia@unicampania.it

Míriam Piqué

miriam.pique@ctfc.cat

Simona Altieri

simona.altieri@unicampania.it
José Ramón González-Olabarria

jr.gonzalez@ctfc.cat

Pere Casals

pere.casals@ctfc.cat

Joint Research Unit CTFC - AGROTECNIO, Ctra de St. Llorenç de Morunys, $\mathrm{km}$ 2, 25280 Solsona, Spain

2 Department of Environmental, Biological and Pharmaceutical Sciences and Technologies, University of Campania "L. Vanvitelli", Via Vivaldi no. 43, 81100 Caserta, Italy 